\title{
Erratum zu: Spear Phishing 2.0: Wie automatisierte Angriffe Organisationen vor neue Herausforderungen stellen
}

\author{
Anjuli Franz $\cdot$ Alexander Benlian
}

Angenommen: 17. Mai 2021 / Online publiziert: 20. September 2021

(C) Der/die Autor(en) 2021

\section{Erratum zu:}

\section{HMD 2020}

https://doi.org/10.1365/s40702-020-00613-y

Der Artikel Spear Phishing 2.0: Wie automatisierte Angriffe Organisationen vor neue Herausforderungen stellen von Anjuli Franz und Alexander Benlian wurde ursprünglich Online First ohne „Open Access“ auf der Internetplattform des Verlags publiziert. Nach der Veröffentlichung in Band 57 Heft 3 pp. 597-612 hatten sich die Autoren für eine „Open Access“-Veröffentlichung entschieden. Das Urheberrecht des Artikels wurde deshalb in (C) Die Autoren 2020 geändert.

Dieser Artikel wird nun unter der Creative Commons Namensnennung 4.0 International Lizenz veröffentlicht, welche die Nutzung, Vervielfältigung, Bearbeitung, Verbreitung und Wiedergabe in jeglichem Medium und Format erlaubt, sofern Sie den/die ursprünglichen Autor(en) und die Quelle ordnungsgemäß nennen, einen Link zur Creative Commons Lizenz beifügen und angeben, ob Änderungen vorgenommen wurden. Die in diesem Artikel enthaltenen Bilder und sonstiges Drittmaterial unterliegen ebenfalls der genannten Creative Commons Lizenz, sofern sich aus der Abbildungslegende nichts anderes ergibt. Sofern das betreffende Material nicht unter der genannten Creative Commons Lizenz steht und die betreffende Handlung nicht nach gesetzlichen Vorschriften erlaubt ist, ist für die oben aufgeführten

Die Online-Version des Originalartikels ist unter https://doi.org/10.1365/s40702-020-00613-y zu finden.

Anjuli Franz $(\bowtie) \cdot$ Alexander Benlian

Technische Universität Darmstadt, Hochschulstraße 1, 64289 Darmstadt, Deutschland

E-Mail: franz@ise.tu-darmstadt.de

Anjuli Franz

IT-Seal GmbH, Hilpertstraße 31, 64295 Darmstadt, Deutschland 


\section{Weiterverwendungen des Materials die Einwilligung des jeweiligen Rechteinhabers} einzuholen.

The original article has been corrected.

Funding Open access funding enabled and organized by Projekt DEAL.

Open Access Dieser Artikel wird unter der Creative Commons Namensnennung 4.0 International Lizenz veröffentlicht, welche die Nutzung, Vervielfältigung, Bearbeitung, Verbreitung und Wiedergabe in jeglichem Medium und Format erlaubt, sofern Sie den/die ursprünglichen Autor(en) und die Quelle ordnungsgemäß nennen, einen Link zur Creative Commons Lizenz beifügen und angeben, ob Änderungen vorgenommen wurden.

Die in diesem Artikel enthaltenen Bilder und sonstiges Drittmaterial unterliegen ebenfalls der genannten Creative Commons Lizenz, sofern sich aus der Abbildungslegende nichts anderes ergibt. Sofern das betreffende Material nicht unter der genannten Creative Commons Lizenz steht und die betreffende Handlung nicht nach gesetzlichen Vorschriften erlaubt ist, ist für die oben aufgeführten Weiterverwendungen des Materials die Einwilligung des jeweiligen Rechteinhabers einzuholen.

Weitere Details zur Lizenz entnehmen Sie bitte der Lizenzinformation auf http://creativecommons.org/ licenses/by/4.0/deed.de. 